\title{
Professores Universitários com Deficiência: trajetória escolar e conquista profissional
}

\author{
Rosimeire Maria Orlando' \\ Katia Regina Moreno Caiado' \\ 'Universidade Federal de São Carlos (UFSCAR), São Carlos/SP - Brasil
}

RESUMO - Professores Universitários com Deficiência: trajetória escolar e conquista profissional. Este estudo tem como foco a educação escolar de pessoas com deficiência. Investigou-se a trajetória escolar de professores universitários, com o objetivo de compreender influências sobre desempenho escolar e identificar razões da distinção que os tornou minoria dentre os milhares de outras pessoas com deficiência que não atingem tal patamar de educação formal e profissionalização. O estudo tem como base teórica os trabalhos de Bourdieu. Optou-se por trabalhar com procedimentos metodológicos de entrevista, questionário e análise de documentos biográficos. Participaram desta pesquisa três professores. $\mathrm{O}$ estudo indica que a valorização familiar pelo estudo, a condescendência da instituição escolar e a distribuição do capital cultural objetivado são indicativos do desempenho escolar e profissional destes sujeitos.

Palavras-chave: Educação Especial. Trajetória Escolar. Ensino Superior.

ABSTRACT - University Teachers with Disabilities: school career and professional achievement. This study focuses on the school education of disabled people. We explored the school path of university teachers in order to understand influences on their scholar performance and to identify the distinctive reasons that made of them a minority among thousands of other disabled people who were not able to achieve such levels of formal education and professionalization. The study is mainly based on Bourdieu's theoretical works. Our methodological procedures were interviews, questionnaires, and analysis of biographical documents. Three teachers participated in the research. This study shows that the family's appreciation of study and school, the condescension of the school institution, and the distribution of the aimed cultural capital are the indicatives of academic and professional performance of these subjects.

Keywords: Special Education. School Career. Higher Education.

Educação \& Realidade, Porto Alegre, v. 39, n. 3, p. 811-830, jul./set. 2014.

Disponível em: <http://www.ufrgs.br/edu_realidade> 
Professores Universitários com Deficiência

\section{Introdução}

O Brasil vivencia, desde o final do século passado e início do século XXI, tempos de amplo destaque no que diz respeito à luta pelos direitos sociais das pessoas com deficiência. Acompanhando o cenário internacional, no contexto pós II Guerra Mundial, a Declaração Universal dos Direitos Humanos (ONU, 1948) deflagrou um processo de internacionalização desses direitos. A conquista efetiva deles, porém, dependerá das lutas travadas no espaço social.

Para Bem (2006), os movimentos sociais são verdadeiros indicadores para a análise do funcionamento da sociedade, pois traduzem o permanente movimento das forças sociais e nos permitem identificar as tensões entre os diferentes grupos de interesses, expondo os mecanismos de luta da sociedade. Gohn (1995) salienta que, no âmbito brasileiro, o século XX pode ser encarado como aquele em que os movimentos sociais efervesceram como fenômenos sociais abrangentes. Foi um período de convergência de forças sociais em torno de lutas comuns e fundamentais à construção da cidadania sociopolítica do país. Nessa direção, desde o início do século XX, a história do Brasil é marcada pelo enfrentamento e lutas sociais, a exemplo da Greve Geral de 1917, considerada uma das mais importantes manifestações políticas da época, ou mais à frente, o período populista (1945-1968), que abriu oportunidade para o avanço de várias formas de participação social - como a disputa político partidária, a revitalização sindical ou movimentos por reforma de base da educação, que tiveram como conclusão a revolta estudantil de 1968 (Bem, 2006; Gohn, 1995).

No que diz respeito aos movimentos sociais das pessoas com deficiência e seus familiares, a década de 1980 teve como principal característica a representação civil das pessoas com deficiência, e não mais dos especialistas. No ano de 1984, por exemplo, fundaram-se a Federação Brasileira de Entidades de Cegos, a Organização Nacional de Entidades de Deficientes Físicos, a Federação Nacional de Educação e Integração de Surdos e o Movimento de Reintegração dos Hansenianos (Bieler, 1990).

Anteriormente, o governo, frente à crescente organização desse segmento, já começava a se estruturar criando em 1973 o Centro Nacional de Educação Especial (Cenesp), responsável por promover a expansão e melhoria do atendimento na Educação Especial no Brasil (Pires, 1974), colaborando para que a década de 1970 fosse marcada pela instalação de um verdadeiro subsistema educacional, com a proliferação de instituições públicas e privadas de atendimento segregado às pessoas com deficiência. Nesse processo, destacam-se a criação da Federação Nacional das APAES (novembro de 1962) e da Federação Nacional das Associações Pestalozzi (agosto de 1970). Além disso, foram criados órgãos normativos tanto em âmbito federal quanto estadual, como os órgãos de Serviços de Educação Especial em todas as Secretarias Estaduais de Educação (Jannuzzi, 2006; Bueno, 1991; 1993; Mazzotta, 1996). 
Nesse período a situação da Educação Especial brasileira contribuía de duas formas para a manutenção do processo de participação-exclusão da camada pauperizada da população, no interior da escola. Primeiro, por se apropriar do conceito de deficiência que acabava colocando somente no âmbito das potencialidades individuais o problema do rendimento escolar. Segundo, por incorporar uma pequena parcela dessa mesma população que ela identificava como com deficiência, a exemplo do estado de São Paulo, que atendia apenas $10,6 \%$ da população com deficiência em idade escolar (Bueno, 1991; 1993). Sendo assim, para Bueno (1993), a Educação Especial as expulsava da escola regular porque eram pessoas com deficiência, e também não as incorporava à Educação Especial, pois não havia atendimento educacional especializado para todos; desta forma, essa população permanecia discriminada, por não apresentar bom nível escolar e também por ser composta por pessoas com deficiência.

Ainda, como marco para a Educação Especial brasileira, em 1987 é criada a Coordenadoria Nacional para a Integração das Pessoas Portadoras de Deficiência (Corde) - órgão responsável por coordenar todas as ações voltadas para a pessoa com deficiência. Há também nesse período a expansão do movimento em âmbito internacional, ampliando sua atuação política e o amadurecimento de suas lideranças (Bieler, 1990).

O trabalho desses movimentos sociais foi decisivo para uma das principais etapas desta luta travada nos anos de 1980, ou seja, uma tentativa de mudança de postura em relação às pessoas com deficiência. Nos dizeres de Bieler, “[...] a tutela é substituída pela plena cidadania” (Bieler, 1990, p. 23).

Nesse contexto de luta e efervescência dos movimentos sociais foi gestada a Constituição Brasileira (1988), com o país vivenciando uma série de movimentos que envolviam inúmeros segmentos da população brasileira na reivindicação por direitos políticos e sociais. Assim, a Carta Cidadã tornou-se um marco e um aporte para a discussão dos diretos sociais. Desde a mobilização da sociedade civil à legislação propriamente dita, percorreu-se um caminho de muitas lutas, dificuldades e conquistas (Lanna Junior, 2010).

Nessa direção, a legislação brasileira é de recente data enquanto instrumento legal na garantia dos direitos de todos e dentre todos, de uma parcela da população, as pessoas com deficiência, até então preocupação da assistência social e da caridade (Pinheiro, 2009).

No âmbito nacional, a Constituição Federal de 1988 (Brasil, 1988) e a Lei n. 9.394, de 1996 (Brasil, 1996), garantem como dever da família e do Estado, a responsabilidade para com os direitos sociais e educacionais das pessoas com deficiências, como matrículas preferencialmente no ensino regular, e a Política Nacional de Educação Especial na Perspectiva da Educação Inclusiva (Brasil, 2008) apresenta a Educação Especial de modo integrado à proposta pedagógica da escola regular.

Educação \& Realidade, Porto Alegre, v. 39, n. 3, p. 811-830, jul./set. 2014

Disponível em: <http://www.ufrgs.br/edu_realidade> 
Professores Universitários com Deficiência

Tais prescrições permitem que aportemos, no final do século XX e início do século XXI, impulsionados tanto pelo cenário internacional quanto nacional, com certo avanço na organização de alguns movimentos sociais que lutam pela garantia dos direitos humanos das pessoas com deficiência, dando destaque à ampla participação de cidadãos - fato que traz diferentes repercussões na forma de conceber e tratar a deficiência, com desdobramentos, inclusive, na educação escolar.

Sabemos que a história da Educação Especial, desde sua origem (Pessotti, 1984; Bueno, 1993; Jannuzzi, 2006), é significativa de exemplos à inobservância dos direitos das pessoas com deficiência, enquanto cidadãs. Atualmente podemos questionar a possibilidade da participação mais efetiva, na sociedade, de uma população que até então se apresentava invisível, pois ora estava segregada em casa, ora em instituições ou até mesmo em classes especiais.

De qualquer forma, a escola brasileira historicamente se caracteriza, há longo período, pela visão da educação que delimita a escolarização da população, tratando a educação como privilégio de um grupo - uma postura que foi legitimada tanto nas políticas quanto na produção científica e nas práticas educacionais reprodutoras da ordem social, reafirmando a exclusão social e educacional de um contingente da população, incluindo aqui as pessoas com deficiência (Brasil, 2008; Patto, 2008; Jannuzzi, 2006).

Para exemplificar as restrições sociais das pessoas com deficiência, o Censo Demográfico de 2010 (Brasil) mostra que somos 190.755 .799 brasileiros; deste total, 8,25\% são pessoas com deficiência permanente (visual, auditiva, motora, mental/ intelectual) ${ }^{1}$. No Brasil há 13.660.168 pessoas analfabetas com 15 anos ou mais. Dentre as pessoas com deficiência nessa faixa etária, 4.645.145 não são alfabetizadas. Portanto, os dados revelam que $34 \%$ das pessoas analfabetas no país têm alguma deficiência. E também mostram que $26,15 \%$ das pessoas com deficiência com 10 anos ou mais sobrevive com 1 a 5 salários mínimos, 22,82\% não possuem rendimento ${ }^{2}$ e a maior parte, $47,50 \%$ sobrevive com a renda de até 1 salário mínimo ${ }^{3}$.

Essa realidade nos permite afirmar que há grande parcela de pessoas com deficiência em nosso país sem acesso aos direitos sociais garantidos pela Constituição Brasileira (1988), conforme estabelecido em seu artigo $6^{\circ}$ :

[...] a educação, a saúde, a alimentação, o trabalho, a moradia, o lazer, a segurança, a previdência social, a proteção à maternidade e à infância, a assistência aos desamparados (Brasil, 1988, p. 13).

Por outro lado, dados oficiais (Brasil, 2010; Inep, 2010) e estudos apontam um crescimento nas matrículas de pessoas com deficiência em todos os níveis e modalidades de ensino, mas sinalizam a dificuldade em atender as demandas de escolarização em todas as etapas, desde 
a educação básica (Bueno; Meletti, 2010; Brasil, 2008), assim como nas áreas rurais (Caiado; Meletti, 2011, 2012).

Assim, são poucos os que conseguem chegar ao ensino superior. Tal fato talvez nos permita dizer que haja indícios de que uma porcentagem bem menor consegue concluir a pós-graduação stricto sensu, e ainda com menor chance de chegar efetivamente à docência do ensino superior, apontando um descompasso na concretização de projetos nesse contexto. Apesar de, recentemente, as políticas públicas assegurarem alguns direitos à pessoa com deficiência, há que se considerar que as práticas sociais e culturais provocam um descompasso na efetivação desse intento.

Para Bourdieu e Passeron (1982) as ações sociais são concretamente realizadas pelos indivíduos, entretanto as chances de efetivá-las se encontram objetivamente estruturadas no interior da sociedade global. Ao pensarmos em uma escola que está inserida em uma sociedade dividida em classes sociais, há que se considerar os conflitos, as desigualdades sociais fortemente presentes, sobretudo quando o assunto é relacionado a pessoas com deficiência e sua escolarização.

Pensando nessa direção, é possível verificar que algumas pessoas com deficiência conseguem driblar esse sistema, concluem o ensino superior, chegam à pós-graduação stricto sensu e concluem seus estudos nesse nível, concretizando a docência no ensino superior - ou seja, se apropriam de dimensões do conhecimento universal e científico ao longo do seu processo de escolarização, apesar das restrições que vivenciaram para a participação social, como apontam os estudos de Caiado et al. (2011).

Bourdieu (2010), analisando a situação francesa, em publicação original datada em 1964, afirmou que um jovem de classe social superior tem 80 vezes mais chance de entrar na universidade que o filho de um assalariado agrícola e 40 vezes mais que o filho do operário. Nessa direção, a situação brasileira é bem mais drástica, pelos dados anteriormente citados, estabelecendo-se um quadro de muitas lutas pela sobrevivência de, por exemplo, pessoas com deficiência em classe social média/inferior, que conseguem driblar esse sistema, ter acesso, permanência e apropriação dos conteúdos curriculares em sua trajetória escolar e alcançar o patamar de profissionalização na docência universitária.

Tais dados se tornam de suma importância quando buscamos indícios para entender, via trajetória escolar, as disposições que promoveram o sucesso escolar de pessoas com deficiência, mesmo diante de uma realidade excludente. Assim, para além dos dados quantitativos, se historicamente sabemos que o conceito de deficiência é sinônimo de incapacidade, certamente a trajetória escolar dessas pessoas traz marcas profundas de muita luta e superação das condições adversas que vivenciaram no cotidiano.

Educação \& Realidade, Porto Alegre, v. 39, n. 3, p. 811-830, jul./set. 2014.

Disponível em: <http://www.ufrgs.br/edu_realidade> 
Professores Universitários com Deficiência

Mais interessante ainda se torna a investigação nessa temática, ao se pensar em quantas estratégias de investimento escolar estiveram presentes, já que:

Não dispondo de informações suficientemente atualizadas para conhecer a tempo as 'apostas' a serem feitas, nem de um capital econômico suficientemente importante para suportar a espera incerta dos ganhos financeiros, nem tão pouco de um capital social suficientemente grande para encontrar uma saída alternativa em caso de fracasso, as famílias das classes populares e média [...] têm todas as chances de fazerem maus investimentos escolares (Bourdieu, 2010, p. 94).

Nessa direção, a questão que se coloca não é somente reafirmar a importância de se garantir a universalização do acesso à educação desse alunado, mas sim questionar as reais condições de acesso, permanência e apropriação devida dos conteúdos escolares. Até mesmo quando pensamos em famílias mais desprovidas de cultura clássica, que após completar seus estudos recebem um diploma desvalorizado (Bourdieu; Passeron, 1982). É, sobretudo, estudar qual a trajetória escolar que trilharam para conseguir chegar à docência no nível superior, com todas as restrições que tiveram para essa participação social.

Certo é que legalmente tais alunos já têm garantida a matrícula na escola regular. Assim, há a importância de pesquisarmos essa realidade, na tentativa de superar os impasses tanto com as aprendizagens quanto no que diz respeito à formação inicial e continuada dos professores, especialistas ou não. Desta maneira, pesquisar a trajetória escolar de pessoas com deficiência que concluíram o ensino superior, a pós-graduação stricto sensu e escolheram a docência no ensino superior como profissão, se torna importante instrumental nessa direção.

A relevância deste estudo fica evidente, também, ao se ampliar os dados de Bueno (2010) que ao estudar a relação entre alunos com deficiência e o ensino superior no Brasil - no período de 1997 a 2006 -, demonstra que, embora exista o interesse em se estudar a temática da pessoa com deficiência no ensino superior, há uma escassez de trabalhos. Quando o assunto são professores universitários com deficiência, o quadro que se coloca não é diferente.

No período de 2000 a 2010, em pesquisa realizada no banco de teses e dissertações da CAPES, realizou-se a leitura de um total de 9.634 títulos e/ou resumos de teses e dissertações; finalizada a análise, localizou-se apenas um estudo voltado para a temática aqui proposta. Trata-se de pesquisa de mestrado realizada em universidade particular da cidade de São Paulo, no ano de 2009, cujo foco foi a trajetória formativa de professores com deficiência física, atuando no ensino superior (Barbosa, 2009). Tal dado revela a escassez de trabalhos acadêmicos que tenham como tema a trajetória escolar de professores universitários com deficiência no ensino superior.

816 Educação \& Realidade, Porto Alegre, v. 39, n. 3, p. 811-830, jul./set. 2014 Disponível em: <http://www.ufrgs.br/edu_realidade> 
Além disso, esse esforço em retomar a trajetória de escolarização dessas pessoas, que, apesar da história de restrição social, conseguiram concluir a pós-graduação stricto sensu e chegar à docência em instituições de ensino superior no Brasil, demonstra considerável contribuição para a área, ao detectar o que os torna tão distintos de tantos outros.

Trabalhos como de Zago (2006), cujo foco é a problemática do estudante universitário oriundo de famílias de baixo poder aquisitivo e reduzido capital cultural, em que se problematiza o que tem se chamado de longevidade escolar, reiteram também o fato de poucos estudos tentarem explicar como algumas pessoas conseguem escapar do círculo vicioso que leva à exclusão e à marginalidade, já que:

[...] uma efetiva democratização da educação requer certamente políticas para a ampliação do acesso e fortalecimento do ensino público, em todos os seus níveis, mas requer também políticas voltadas para a permanência dos estudantes no sistema educacional de ensino (Zago, 2006, p. 228).

Tal fato talvez nos ajude a problematizar afirmações na produção em educação que ainda consideram o sistema escolar como importante fator de mobilidade social. Para Bourdieu (2011), o sistema escolar, ao contrário, tende a mostrar que é um dos fatores mais eficazes e potentes para conservação social.

Por outro lado, quando Nogueira (2002) se interessa pela trajetória de escolarização de jovens originários de lares altamente favorecidos, do ponto de vista do capital cultural e econômico, mas que experimentam o fracasso escolar, fica claro o fato de que os pais se mostram absolutamente céticos quanto à capacidade da escola em garantir ao filho uma manutenção ou ampliação desse capital cultural e econômico. As trajetórias verificadas mantêm uma distância considerável da excelência escolar.

Para Bourdieu (2007),

As atitudes dos membros das diferentes classes sociais, pais ou crianças e, muito particularmente, as atitudes a respeito da escola, da cultura escolar e do futuro oferecido pelos estudos são, em grande parte, a expressão do sistema de valores implícitos ou explícitos que eles devem a sua posição social (Bourdieu, 2007, p. 46).

Ao investigar trajetórias de alunos de diferentes níveis sociais, o que nos impulsiona é compreender quais disposições contribuem para que o aluno com deficiência tenha acesso e permanência no sistema escolar e a apropriação devida dos conteúdos escolares para a participação social?

Nessa perspectiva, o presente trabalho tem como objetivo investigar a trajetória escolar de professores com deficiência que atuam no ensino superior para compreender as influências sobre seu desempe-

Educação \& Realidade, Porto Alegre, v. 39, n. 3, p. 811-830, jul./set. 2014. 
nho escolar e identificar razões da distinção desses agentes que os tornaram uma pequena minoria dentre milhares de outras pessoas com deficiência que não atingem tal patamar de educação formal e profissionalização.

Nessa direção, o presente estudo tem como base teórica principalmente os trabalhos de Bourdieu e seus colaboradores, por termos localizado, nesse referencial, fundamentos que possibilitam identificar as disposições que influenciam tanto os êxitos quanto os fracassos dos diferentes sujeitos oriundos dos diversos meios sociais.

Neste estudo, entende-se a constituição do ser humano enquanto síntese das relações sociais, marcada em um tempo e espaço. Assim, o homem em relação com outros homens se constitui humano entre múltiplas determinações, com condicionantes históricos complexos e diversos (Gramsci, 1978). Entende-se a trajetória escolar enquanto prática social que será apreendida nas narrativas dos participantes.

Esta pesquisa,

[...] pautou-se numa visão de mundo materialista dialética em que se entende como método de estudo o movimento investigativo que tem seu ponto de partida nas práticas sociais e nelas retorna como ponto de chegada. Entende-se que como ponto de partida a vida se apresenta enquanto fato espontâneo e descontextualizado. Será no processo de estudo e de análise que se encontrarão a historicidade e multideterminação das práticas sociais e desse modo pode-se, então, retomar a vida em sua complexidade e com esse conhecimento, sobre ela agir (Caiado, 2013, p. 13).

No estudo da trajetória escolar de pessoas com deficiência, não se considera a trajetória individual do sujeito pesquisado como algo lógico em um percurso linear; mas sim, que esse sujeito se enreda nas forças sociais não necessariamente coerentes, quando é levado a optar, por exemplo, pelos estudos (Lahire, 2004).

As posições sociais ocupadas pelos professores universitários com deficiência, em sua trajetória escolar anterior à docência no ensino superior, foram consideradas como expressões de concretas condições de existência, e constituíram elementos importantes para a coleta e análise do material, com o intuito de buscar indícios que permitissem estudar como conseguiram chegar à docência do ensino superior apesar de todas as restrições que vivenciaram na participação social, enquanto pessoas com deficiência.

Para realizar o presente estudo optou-se por trabalhar com entrevista, questionário e análise de documentos biográficos. Participaram desta pesquisa três professores universitários: dois do sexo masculino um com deficiência múltipla (deficiência física e baixa visão) e outro com deficiência visual - e uma do sexo feminino, com deficiência auditiva. 
O convite para participação na pesquisa foi realizado por correio eletrônico, por meio do qual se explicitaram os propósitos do estudo.

As entrevistas foram realizadas pessoalmente, transcritas e analisadas. Os questionários completaram dados referentes à escolarização dos antepassados e indicadores sociais e culturais. A análise documental restringiu-se a consultas ao currículo Lattes de cada participante. A análise dos dados teve como base o perfil dos participantes e os traços familiares, ou seja: contexto familiar e dados biográficos.

As entrevistas foram realizadas em local e horários convenientes aos participantes, com duração de duas horas de gravação. Após a transcrição, as entrevistas foram apresentadas aos participantes para leitura e concordância com a utilização do documento, quando foi assinado o Termo de Consentimento Livre e Esclarecido (TCLE).

Cientes dos objetivos do trabalho e da importância da entrevista e do questionário, os encontros transcorreram envoltos em um ambiente favorável à conversação, resultando em grande riqueza de dados, como se pode ver no recorte a seguir apresentado, quando suscitados a falar sobre a família e sua trajetória escolar.

\section{O Papel das Instituições nas Trajetórias de Vida: família e escola}

Para compreender esse contexto, são relatadas as análises quanto ao perfil dos participantes e dos seus familiares e a interface com o fluxo escolar. Os sujeitos, docentes universitários, serão denominados doravante Professor Pedro, Professor Lucas e Professora Clara - nomes fictícios que preservarão o anonimato dos participantes.

\section{Professor Pedro: da capital paulista à docência universitária}

\section{a) Origem Social: a escolarização como valor familiar}

O Professor Pedro, desde o contato inicial para realização da entrevista e questionário, mostrou-se sempre disposto a participar e, no momento de realização, apresentou com prazer toda sua trajetória escolar, relatando com entusiasmo os momentos de luta e superação das barreiras impostas, de conquistas e de sua docência no ensino superior. Preocupado com a ordem cronológica dos acontecimentos, apresentou um traço significativo em sua fala: uma memória perspicaz.

Ele possui deficiência múltipla, associada à baixa visão, e sequelas de sua prematuridade no nascimento. Relatou a dificuldade em obter um diagnóstico adequado e seguro de sua deficiência, feito apenas recentemente.

Sempre residiu em casa própria, viveu sua infância até os oito anos na capital paulista, mudando-se depois com a família (pais e um

Educação \& Realidade, Porto Alegre, v. 39, n. 3, p. 811-830, jul./set. 2014

Disponível em: <http://www.ufrgs.br/edu_realidade> 
Professores Universitários com Deficiência

irmão mais velho) para cidade do interior do mesmo Estado. Enquanto morador da capital, dentre as atividades de lazer que realizava durante sua infância, menciona visitas ao Museu do Ipiranga e à casa de parentes mais próximos, local em que brincava muito com primos da mesma faixa etária.

Quando questionado sobre a escolarização de antecedentes familiares, relatou que os avós maternos, tinham o ensino fundamental incompleto, sendo a avó costureira e o avô artífice. Os avós paternos, por sua vez, tinham também o fundamental incompleto, sendo que a avó se dedicava aos afazeres domésticos e o avô era funcionário público.

Seus pais cursaram o ensino fundamental em escola da zona rural, concluindo a $4^{\text {a }}$ série. O pai prosseguiu os estudos com o supletivo e concluiu o ensino médio, sendo considerado autodidata pelo entrevistado, realizou estágio em um instituto de pesquisa, permanecendo por lá e se dedicando à área hematológica, como funcionário público. Embora a mãe tivesse concluído apenas a primeira etapa do ensino fundamental e se dedicasse aos afazeres domésticos, afirma que ela escrevia muito bem, com letra bonita e domínio da aritmética, apontando assim, sucesso na alfabetização e investimento na escolarização, em contrapartida ao trabalho manual. Atualmente ambos são falecidos.

\section{b) Trajetória Escolar e Docência Superior: a longevidade escolar}

No momento da entrevista o Professor Pedro nos relatou ter 55 anos, ser casado e viver em uma cidade do interior paulista com sua esposa e filho, que cursava o ensino superior.

Sua escolarização na educação básica se deu em escolas públicas. No ensino superior, cursou licenciatura em Serviço Social, em faculdade particular no interior paulista, no período entre 1977 e 1980. A pós-graduação cursou em universidades públicas: o mestrado no período entre 1981 e 1988 e o doutorado entre 1992 e 1997.

Atualmente dedica-se exclusivamente à carreira acadêmica. É professor assistente doutor em uma universidade pública estadual, e também professor (permanente, no Programa de Pós-Graduação em Educação) titular em uma universidade particular. É também professor colaborador em Programa de Pós-Graduação em Educação Escolar em uma universidade estadual. É líder e membro de grupo de pesquisa na área, editor científico e membro de conselho editorial de revistas científicas. Tem experiência de 27 anos no ensino de graduação nas áreas de Serviço Social e Educação e oito anos na pós-graduação em Educação.

Professor Pedro, em seu relato, deixa explícito o gosto pelos estudos e, hoje, o prazer pela docência e pelo conhecimento, sobretudo de autores críticos.

Ao longo de sua escolarização, Professor Pedro, à exceção da graduação, cursada em instituição privada, sempre estudou em sala 
comum de escola pública, sendo uma exceção à sua época, afeita à segregação, apontando assim, um tratamento diferenciado, na direção de permissão de estudos na rede regular de ensino. Seu irmão mais velho, hoje casado, possui escolaridade superior e também é professor universitário em universidade pública. Ambos, do ponto de vista da formação acadêmica, conseguiram ultrapassar os limites impostos pela origem familiar. Pedro o considera, juntamente com a mãe, apoios importantes em sua escolarização, com forte investimento na leitura e na escrita dado que cabe ser destacado, percebido não só em sua trajetória escolar, mas também de seus antepassados.

\section{Professor Lucas: alegria e luta pelas conquistas do improvável}

\section{a) Origem social: a escolarização como valor familiar}

Tranquilidade, segurança, entusiasmo e envolvimento. Tais características foram traços marcantes e fortemente presentes na fala do Professor Lucas, no transcorrer da entrevista, que foi marcada por sua alegria.

Ele é cego, lembra que começou a perder a visão ainda menino, com oito para nove anos de idade, e relata a dificuldade na época para se obter um diagnóstico correto, fato que marcou profundamente sua escolarização, realizada em salas comuns de escolas públicas.

Alegre, sempre ligado à música, chegou até a produzir um disco e cantar em bares noturnos. Em sua infância, também gostava muito de pescar em rio na companhia do pai, nadar, fazer desenhos com a família e brincar em uma estação de trens próxima a sua casa. Ressalta que na adolescência as atividades com música, teatro, acampamentos, campeonato de xadrez e, sobretudo, atividades em equipe e culto religioso foram marcantes. Sempre morador da zona urbana, relata que residiu com a família em casa alugada e própria.

Sobre seu pai, relata ter 61 anos, ser funcionário público e só ter concluído o ensino superior quando o entrevistado já era adulto. Sua mãe concluiu o ensino supletivo no final da década de 90, e terminou o antigo curso de Magistério (ensino médio), mas sempre se dedicou apenas ao trabalho do lar.

Ele é o filho mais velho do casal. Sua irmã, quatro anos mais nova, também se dedica ao magistério, hoje é casada, atua na área das ciências exatas e realiza o segundo curso superior na área de educação. Já seu irmão, o caçula da família, oito anos mais novo, é solteiro, concluiu o ensino médio e não prosseguiu os estudos no âmbito superior - dedica-se ao trabalho de corretor de seguros.

Cortadora de cana, ou seja, trabalhadora rural, sua avó materna cursou o antigo MOBRAL (Movimento Brasileiro de Alfabetização) ${ }^{4}$ na esperança de se escolarizar. Seu avô paterno, pedreiro, por sua vez rea-

Educação \& Realidade, Porto Alegre, v. 39, n. 3, p. 811-830, jul./set. 2014

Disponível em: <http://www.ufrgs.br/edu_realidade> 
Professores Universitários com Deficiência

lizou curso técnico no antigo Instituto Universal Brasileiro (IUB) ${ }^{5}$. Sua avó paterna é considerada pelo entrevistado uma autodidata na escolarização e se dedicava às tarefas domésticas, já seu avô paterno, também alfabetizado, era caminhoneiro.

\section{b) Trajetória Escolar e Docência Superior: a longevidade escolar}

À época da entrevista ele contava apenas 39 anos. Com uma rápida trajetória acadêmica licenciou-se em Física no ano de 1995, concluiu em 2000 seu mestrado em Educação para a Ciência, doutorou-se em Educação no ano de 2005 e no ano seguinte fez pós-doutorado, realizando todos os seus estudos em universidade pública, no interior paulista.

É docente no Departamento de Física e Química de universidade pública e no Programa de Pós-Graduação em Educação para a Ciência, em que também orienta trabalhos relacionados ao ensino de ciências e à inclusão de alunos com deficiências. Leciona disciplinas tanto para os cursos de licenciatura em Física, Matemática e Biologia, bem como, para os cursos de Engenharia e para os cursos de mestrado e doutorado, sendo responsável por disciplinas relacionadas à inclusão escolar de alunos com deficiência. Coordena grupo de pesquisa, tem experiência no campo da Educação, com ênfase em Ensino de Ciências, atuando principalmente com a temática do ensino de física para alunos com deficiência visual.

\section{Professora Clara: estimulação e independência}

\section{a) Origem social: a escolarização como valor familiar}

Por vezes oralizando, outras utilizando a Língua Brasileira de Sinais (LIBRAS) a Professora Clara, se mostrou atuante e independente em sua entrevista. Conforme já afirmado, foi a única do sexo feminino, do grupo de entrevistados.

É a segunda filha de um casal, foi diagnosticada precocemente com surdez profunda e menciona que recebeu atendimento fonoaudiológico desde os 11 meses de idade. Quando ainda era criança, ressalta que sua mãe custeou um curso de Língua Brasileira de Sinais (LIBRAS), para uma fonoaudióloga da cidade, para poderem se comunicar. Recebia também, em seu período escolar, apoio constante de uma pedagoga.

Quando questionada sobre os antecedentes familiares, menciona que a avó materna possuía o ensino médio completo e se dedicava aos afazeres domésticos, o avô materno, por sua vez, com superior completo, era bancário. A avó paterna também possuía ensino médio completo, da mesma forma que seu avô paterno, sendo que ela se dedicava ao lar e ele tinha a profissão de locutor de rádio.

Seu pai, hoje com 61 anos, tem o ensino superior completo em Biomedicina, sendo proprietário de um laboratório de análises clíni- 
cas e diretor de um curso de pós-graduação em instituição de ensino superior particular. Sua mãe, com 58 anos, realizou sua graduação em Medicina, e prosseguiu os estudos até o doutorado, sendo hoje docente em universidade pública. Possui três irmãs, a mais velha e mais nova possuem graduação em Direito e exercem a profissão, a caçula, meia-irmã hoje com 17 anos, cursa o ensino médio.

\section{b) Trajetória Escolar e Docência Superior: a longevidade escolar}

Na época da entrevista Clara contava 29 anos, hoje é casada e relata que reside em casa própria, na zona urbana do interior paulista.

No período de 2000 a 2004, realizou graduação em Ciência da Computação, em centro universitário particular, em cidade do interior paulista, momento em que realizou Trabalho de Conclusão de Curso sobre a aplicação da informática na educação e comunicação do surdo. De 2006 a 2008 cursou o Mestrado em Educação, em universidade pública no estado de Santa Catarina, aprofundando seus estudos sobre a cultura surda e sobre os processos de inclusão na escola regular. Iniciou o doutorado em 2011, também em universidade pública, dedica-se à pesquisa sobre as estratégias do ensino de segunda língua (LIBRAS) para alunos universitários do Ambiente Virtual de Ensino Aprendizagem (AVEA) e do ensino presencial.

Em início de carreira, faz parte do corpo docente de estudos surdos e LIBRAS em um centro universitário da cidade em que reside. Também é docente responsável pela disciplina LIBRAS na modalidade de ensino a distância em curso de Educação Musical de universidade pública.

Atuante, é também diretora de educação e cultura da Associação de Surdos de sua cidade. Informa que atua em pesquisas principalmente nos temas relacionados aos estudos surdos, informática na educação de surdos, LIBRAS, cultura surda, política, tecnologia especializada, comunidade surda, pedagogia, inclusão e diferença cultural.

Já trabalhou em centro universitário particular como professora convidada, realizou estágio, participou de conselhos municipais e associações de surdos e trabalhou em universidade pública como professora pesquisadora, substituta e convidada. Já publicou capítulos de livros e em anais de congressos, participou em bancas de trabalhos de conclusão de curso e na organização de eventos.

\section{Ação Familiar e Êxito Escolar: a herança cultural}

Pensando, então, a partir dos estudos de Bourdieu e seus colaboradores, é possível descrever e analisar a trajetória escolar de professores com deficiência que atuam no ensino superior, na tentativa de compreender as influências sobre seu desempenho escolar.

Educação \& Realidade, Porto Alegre, v. 39, n. 3, p. 811-830, jul./set. 2014.

Disponível em: <http://www.ufrgs.br/edu_realidade> 
Professores Universitários com Deficiência

Os antecedentes familiares dos três professores - Pedro, Lucas e Clara - revelam tentativas de conquistas escolares e sociais presentes em gerações anteriores. Os avós de Clara finalizaram a educação básica, eram famílias representantes de uma pequena elite letrada no país. Os avós de Pedro e Lucas, ambos de origem social simples, fazem um forte investimento familiar na alfabetização inicial, dentre, é claro, as possibilidades na época oferecidas às camadas populares. Escola rural, ensino supletivo, MOBRAL, ensino a distância, são espaços de escolarização que atestam o quanto essas famílias valorizavam o aprendizado escolar. Enquanto trabalhadores, os avós dos professores Pedro e Lucas não concluíram o ensino fundamental, mas investiram na primeira etapa, garantindo a apropriação da leitura e da escrita.

Os pais, por sua vez, avançaram no patamar de escolarização, quando comparado com a geração anterior: todos concluíram a etapa do ensino médio. O pai do Professor Lucas, depois que os filhos estavam mais velhos, concluiu o ensino superior, garantindo primeiramente a escolarização da prole; ambos os pais de Clara possuíam ensino superior completo, a mãe com doutorado concluído.

Na sequência, os sujeitos desta pesquisa concluíram o ensino superior e a pós-graduação. Assim, Pedro e Lucas conseguiram avançar o patamar de estudos, quando comparado com a geração anterior, e Clara conseguiu manter o mesmo patamar de escolarização de seus pais. São famílias e realidades diferentes, mas que, ao mesmo tempo, mantêm uma singularidade, com decisões que traduzem uma intencionalidade, ou seja, o investimento na escolarização, desde a busca pelo domínio da leitura e da escrita até a formação de pesquisadores, concretizada na qualificação dos netos.

É importante salientar que, segundo Bourdieu (2010), cada família transmite aos seus filhos certo capital cultural, um sistema de valores implícitos e profundamente interiorizados, que contribui para definir, entre outras coisas, as atitudes face ao capital cultural e à instituição escolar. Assim, a ação do meio familiar sobre o êxito escolar é quase exclusivamente cultural. A herança cultural é a responsável pela diferença inicial das crianças diante da experiência escolar e, consequentemente, pelas taxas de êxito. Vários excertos das entrevistas nos remetem a isso, como exemplo:

O auxílio que tanto minha mãe, meu pai e meu irmão, os três membros da família me deram foi com a leitura... Para eu poder ler mais rápido e também para a memória auditiva (Prof. Pedro).

Minha irmã no mestrado foi minhas mãos e meus olhos... (Prof. Lucas).

O meu avô explicava, minha avó, os dois sempre me incentivando a leitura... (Profa. Clara).

Segundo Bourdieu e Passeron (2010; 2011), as perspectivas de uma família em relação à escola condicionam a trajetória de seus filhos; o sucesso escolar não é uma questão de “dom” - na verdade é uma orien- 
tação precoce que procede do meio familiar. É entendida como uma ação direta dos hábitos culturais familiares e as disposições herdadas do meio de origem que são reforçadas pela lógica escolar. A exemplo, podemos citar alguns excertos das entrevistas sobre as atitudes familiares frente ao universo escolar.

Minha mãe, ela não auxiliava não. Era o seguinte: ela só disciplinava "agora você vai fazer sua tarefa"... (Prof. Pedro).

A participação da minha família na minha escolarização foi cem por cento. Se eu tenho as coisas que tenho, eu devo a eles... (Prof. Lucas).

A minha mãe queria me colocar em outra escola que era um pouco mais forte... (Profa. Clara).

Pensando nos modos como cada sujeito focalizou suas experiências, sobretudo no enfrentamento de situações escolares vivenciadas, foi possível verificar que tais ações frente aos impasses da escolarização decorrem de um longo processo de valorização da escola, iniciado na família. Ao longo desse processo são múltiplas as interferências que levam os sujeitos, incluindo aqui com destaque os docentes universitários com deficiência, a adquirirem um capital cultural.

Nesse conjunto de incorporações estão as relativas aos modos de pensar, sentir e agir ligados às questões de superação dos obstáculos e enfrentamento dos desafios impostos inicialmente às famílias, e posteriormente no decorrer de suas vidas.

Os três sujeitos apontam em suas trajetórias exemplos de situações em que o valor da escolarização pela família se impunha com forte influência em suas vidas, com estratégias de leitura, escrita, de incentivo para frequentar a escola, na realização das tarefas, entre outros. Mas, além disso, cabe destacar o papel da instituição escolar na construção da excelência escolar desses sujeitos.

Pedro relata em sua trajetória escolar, momentos em que o irmão e a mãe foram importantes apoios - com o aval da escola - na realização dos trabalhos escolares, apontando assim, uma diferença que vai além do investimento familiar na escolarização, qual seja a condescendência da escola para com sua presença na classe comum e o apoio da família de forma diferenciada - por exemplo, quando lhe era permitido que $o$ irmão realizasse as tarefas de artes em seu lugar, ou quando assistia a aulas sem a exigência de fazer as atividades.

A professora disse: você leva o caderno de desenho para casa e seu irmão faz para você (Prof. Pedro).

Da mesma forma, Lucas parte de uma condição diferenciada: fica cego já alfabetizado, com uma base de formação escolar. A presença da família tem um valor marcado em sua trajetória escolar, e da mesma forma a instituição escolar permite exceções para que ele continue os estudos, seja no papel de um amigo auxiliando em sala, ou da irmã "sendo meus olhos", como afirmou na entrevista; ou com o auxílio da mãe:

Educação \& Realidade, Porto Alegre, v. 39, n. 3, p. 811-830, jul./set. 2014.

Disponível em: <http://www.ufrgs.br/edu_realidade> 
Professores Universitários com Deficiência

A mãe sempre me ajudava a copiar, ditava, estudava comigo (Prof. Lucas).

Em uma sociedade de classes fortemente marcadas, como a brasileira, Clara tinha avós e pais com certa distinção, tanto no que diz respeito ao capital cultural, quanto social ou econômico. Desde os avós, contava com o apoio e o incentivo em sua escolarização. Sua mãe, por exemplo, sabia da importância de se estudar em uma escola que oferecesse um padrão de qualidade melhor.

De modo geral, a escolarização foi importante em suas vidas, mas mais que isso, a ocupação também o foi. Percebe-se um avanço nas duas direções. Os três sujeitos, independente de seus diferentes antecedentes econômicos, sociais ou culturais, tinham o valor dos estudos fortemente arraigado em suas trajetórias familiares. As estratégias familiares foram dando suportes na trajetória escolar destes, e a escola, a seu turno, foi permitindo que a família prestasse determinados apoios, nada comuns, como vimos no início deste texto, em períodos anteriores à Constituição Federal de 1988 (Brasil, 1988).

\section{Algumas Considerações}

Retornamos a nossa pergunta: quais disposições contribuem para que a pessoa com deficiência tenha, além do acesso e a permanência no sistema escolar, a apropriação devida dos conteúdos escolares, e construa a excelência escolar?

Partindo deste questionamento, o presente estudo teve o objetivo de conhecer a trajetória escolar de professores com deficiência que atuam no ensino superior e compreender as influências sobre seu desempenho escolar, identificando razões da distinção desses agentes que os tornaram uma pequena minoria dentre milhares de outras pessoas com deficiência que não atingem tal patamar de educação formal e profissionalização.

Os professores Lucas e Pedro, embora tenham se afastado há mais tempo que a Professora Clara dos bancos escolares na posição de alunos, apresentaram em seus relatos clareza e vivacidade nos detalhes de suas trajetórias dentro das escolas, sobretudo nos investimentos escolares. Tal fato nos indica, da mesma forma que aponta Rego (2003) o quanto nenhum deles foi indiferente à escola. Mais que isso, além da posição que a escola ocupa na vida de cada um, percebe-se o investimento na escolarização dispendido pela família, seja na figura de irmão, irmã, avó, mãe ou pai - ou fora dela, de um professor -, para que se garantisse inicialmente o domínio da leitura e escrita.

Os três sujeitos desta pesquisa, embora tenham nos apresentado um traço comum de profissionalização, qual seja, lidar com a produção e disseminação dos conhecimentos, relatam trajetórias escolares nada homogêneas. Porém, há certa regularidade nas tentativas de conquistas escolares e sociais, expressa no investimento familiar pela escolarização, que se pôs com intencionalidade, ainda que com realidades sociais 
diferenciadas de cada família. Além disso, cabe frisar a condescendência da instituição escolar para tratamento diferenciado, seja permitindo o apoio da família na realização das tarefas escolares, como, por exemplo, quando permitiam que estas fossem realizadas em casa, com apoio do irmão de Pedro, já que este fazia todos os desenhos em seu caderno, ou até quando permitiam somente sua presença física nas aulas, sem cobranças das atividades escolares; ou a entrada de Lucas na escola durante o período de férias, para usar a lousa, abrindo, assim, exceções na realização das tarefas escolares, em época em que pouco ou nada se falava sobre direitos sociais ou direitos da pessoa com deficiência à escolarização.

Nesse ponto, vale retomar o pensamento de Bourdieu (2010), para que esse dado possa ser melhor entendido, ao afirmar que é a família que transmite a sua prole certo capital cultural (valores implícitos e interiorizados) que contribuirão para definir, também, as atitudes face à instituição escolar - fazendo com que a ação do meio familiar sobre o êxito escolar seja quase que exclusivamente a herança cultural. Isso fica mais forte quando retomando o que foi discutido, de acordo com Bourdieu e Passeron $(2010 ; 2011)$, que o sucesso escolar é posto como uma orientação que procede da família.

Certos de que as questões que envolvem a escolarização de pessoas com deficiência não podem ser discutidas e refletidas distantes da sociedade em que estão inseridas e dos sujeitos que as vivenciam, estamos conscientes dos desafios que se colocam, sobretudo sobre as possibilidades ou dificuldades com a aprendizagem do conteúdo escolar, papel social da escola.

Para ficar mais claro, finalizamos com o relato de Lucas, sobre como se vê:

[...] um sujeito que está entrando em um mato fechado, porque não foram fáceis minhas experiências - nem como aluno, nem como professor... Eu tive muita teimosia, eu acho que a função da pessoa com deficiência é meio como entrar numa mata fechada, com uma foice - que nem esses que entraram no Brasil -, e vai, e você vai se arranhando, se machucando. Mas o que se há de fazer? Não tem jeito. Esperar que a sociedade olhe, não tem jeito, você não acha?

Assim, longe de propor aspectos universais ou homogêneos, quando o assunto é pessoas com deficiência e trajetória escolar, como aqui proposto, o presente estudo indica que a valorização familiar pelo estudo, pela escola, a condescendência da instituição escolar e a distribuição do capital cultural objetivado, cuja forma por excelência é a escrita (Bourdieu, 2010), são indicativos da excelência escolar e profissional destes sujeitos. 
Professores Universitários com Deficiência

\section{Notas}

1 Conforme o IBGE, com a autodeclaração as pessoas afirmavam ter as seguintes características: não conseguem de modo algum ou têm grande dificuldade na capacidade visual, auditiva, motora, mental/intelectual.

2 Pessoas que recebem somente o Benefício de Prestação Continuada da Assistência Social; o BPC foi instituído pela Constituição Federal de 1988 e regulamentado pela Lei Orgânica da Assistência Social - LOAS, Lei no 8.742, de 7 de dezembro de 1993, pelas Leis no 12.435 , de 06 de julho de 2011 e pela Lei $\mathrm{n}^{\circ} 12.470$, de 31 de agosto de 2011, que alteram dispositivos da LOAS, e pelos Decretos no 6.214 , de 26 de setembro de 2007 e no 6.564 , de 12 de setembro de 2008 (Brasil, 2012).

3 Valor do salário mínimo utilizado no censo: $\mathrm{R} \$ 510,00$.

4 Criado em 1967, surgiu como um prosseguimento das campanhas de alfabetização de adultos iniciadas com Lourenço Filho. Criado pela Lei no 5.379 , de 15 de dezembro de 1967, propunha a alfabetização funcional de jovens e adultos negando a análise das contradições sociais inerentes ao sistema capitalista (Bello, 1993).

5 O Instituto Universal Brasileiro (IUB) surgiu em 1941, como entidade de ensino livre, oferecendo cursos por correspondência, e pode ser considerado um dos primeiros em nosso país objetivando a formação profissional de nível elementar e médio (Saraiva, 1996).

\section{Referências}

BARBOSA, Frederico K. Professores com Deficiência Física no Ensino Superior: estudo de trajetórias escolares. 2009. 93 f. Dissertação (Mestrado em Educação) - Universidade Metodista de São Paulo, São Bernardo do Campo. 2009.

BELLO, José Luiz P. Movimento Brasileiro de Alfabetização-MOBRAL: história da Educação no Brasil. Período do Regime Militar. Pedagogia em Foco, Vitória, p. 1-17. 1993. Disponível em: <http://www.pedagogiaemfoco.pro.br/heb10a. htm>. Acesso em: 5 mar. 2013.

BEM, Arin S. Centralidade dos Movimentos Sociais na Articulação entre o Estado e a Sociedade Brasileira nos Séculos XIX e XX. Educação e Sociedade, Campinas, v. 27, n. 97, p. 1137-1157, 2006.

BIELER, Rosangela B. (Org.). Ética e Legislação: os direitos das pessoas portadoras de deficiência no Brasil. Rio de Janeiro: Rotary Club, 1990.

BOURDIEU, Pierre. Escritos de Educação. 7. Ed. Seleção e Organização: Maria Alice Nogueira e Afrânio Catani. Rio de Janeiro: Editora Vozes, 2010.

BOURDIEU, Pierre. A Economia das Trocas Simbólicas. 6. Ed. Organização e Seleção: Sergio Miceli. São Paulo: Perspectiva, 2011.

BOURDIEU, Pierre; PASSERON, Jean. C. A Reprodução: elementos para uma teoria do sistema de ensino. Tradução Reynaldo Bairão. 2. Ed. Rio de Janeiro: Livraria Francisco Alves Editora AS, 1982.

BRASIL. Constituição da República Federativa do Brasil. Edição Especial. Ecyclopaedia Britannica do Brasil, 1988.

BRASIL. Câmara dos Deputados. Lei Federal no 9.394, de 20 de dezembro de 1996. 1996. 
BRASIL. Ministério da Educação. Secretaria de Educação Especial. Política Nacional de Educação Especial na Perspectiva da Educação Inclusiva. 2008.

BRASIL. IBGE. Instituto Brasileiro de Geografia e Estatística. Censo Demográfico. 2010. Disponível em: <http://www.sidra.ibge.gov.br>. Acesso em: 1 fev. 2012.

BRASIL. Ministério da Educação. CAPES. Banco de Teses. 2011. Disponível em: <http://www.capes. gov.br/servicos/bancoteses.html>. Acesso em: 1 ago. 2011.

BRASIL. Ministério do Desenvolvimento Social e Combate à Fome. Benefício de Prestação Continuada da Assistência Social - BPC-LOAS ao idoso e à pessoa com deficiência. 2012. Disponível em: <http://www.previdencia.gov.br/conteudoDinamico.php?id=23>. Acesso em: 6 dez. 2012.

BUENO, José Geraldo S. Educação Especial Brasileira: a integração do aluno diferente. 1991. 214 f. Tese (Doutorado em Educação) - Pontifícia Universidade Católica de São Paulo, São Paulo, 1991.

BUENO, José Geraldo S. Educação Especial Brasileira: integração/segregação do aluno diferente. São Paulo: EDUC, 1993.

BUENO, José Geraldo S. Deficiência e Ensino Superior: balanço das dissertações e teses brasileiras (1987/2005). In: VICTOR, Sonia. L; DRAGO, Rogério; CHICON, José F. (Org.). A Educação Inclusiva de Jovens, Adolescentes e Adultos: avanços e desafios. Vitória: EDUFES, 2010. P. 255-272.

BUENO, José Geraldo S.; MELETTI, Silvia Marcia F. Escolarização de Alunos com Deficiência: uma análise dos indicadores sociais no Brasil (1997-2006). In: XV ENCONTRO NACIONAL DE DIDÁTICA E PRÁTICA DE ENSINO. Anais... Minas Gerais: UFMG, 2010. P. 1-17.

CAIADO, Katia Regina M. (Org.). Trajetórias Escolares de Alunos com Deficiência. São Carlos: EDUFSCar, apoio FAPESP, 2013.

CAIADO, Katia Regina M.; MELETTI, Silvia Marcia F. Educação Especial no Campo: 20 anos de silêncio no GT 15. Revista Brasileira de Educação Especial, v. 17, p. 93-104, 2011. Edição Especial.

CAIADO, Katia Regina M.; MELETTI, Silvia Marcia F. Educação Especial na Educação do Campo no Estado de São Paulo: uma interface a ser construída. In: ALMEIDA, Maria I. et al. (Org.). Políticas Educacionais e Impactos na Escola e na Sala de Aula. Araraquara: Junqueira\&Marin, 2012.

CAIADO, Katia Regina Moreno; ZEPPONE, Rosimeire Maria Orlando. Educação e Deficiência na Voz de quem Viveu essa Trama: apoios e atendimentos durante a trajetória escolar. In: JESUS, Denise Meyrelles; BAPTISTA, Claudio Roberto; CAIADO, Katia Regina Moreno (Org.). Prática Pedagógica na Educação Especial. Araraquara: Junqueira Marin/Capes, 2013. P. 235-252.

GOHN, Maria G. História dos Movimentos e Lutas Sociais: a construção da cidadania dos brasileiros. São Paulo: Loyola, 1995.

GRAMSCI, Antonio. Concepção Dialética da História. 3. Ed. Rio de Janeiro: Civilização Brasileira, 1978.

INEP. Instituto Nacional de Estudos e Pesquisas Educacionais Anísio Teixeira. Censo Escolar/MEC/INEP. 2010. Disponível em: <http://portal.inep.gov.br/basica-censo>. Acesso em: 31 dez. 2011.

JANNUZZI, Gilberta M. A Educação do Deficiente no Brasil: dos primórdios ao início do século XXI. 2. Ed. Campinas, São Paulo: Autores Associados, 2006.

LAHIRE, Bernard. Retratos Sociológicos: disposições e variações individuais. Tradução: Didier Martin e Patrícia C. R. Reuillard. Porto Alegre: Artmed, 2004. 
LANNA JUNIOR, Mario Cleber M. História do Movimento Político das Pessoas com Deficiência no Brasil. Brasília: secretaria de direitos humanos. Secretaria Nacional de Promoção dos Direitos da Pessoa com Deficiência, 2010.

MAZZOTTA, Marcos José S. Educação Especial no Brasil: história e políticas públicas. São Paulo: Cortez, 1996.

NOGUEIRA, Maria A. Estratégias de Escolarização em Famílias de Empresários. In: ALMEIDA, Ana Maria F.; NOGUEIRA, Maria A. (Org.). A Escolarização das Elites: um panorama internacional de pesquisa. Petrópolis, Rio de Janeiro: Vozes, 2002. P. 49-55.

ONU. Declaração Universal dos Direitos Humanos. 1948. Disponível em: $<$ http://portal.mj.gov.br/sedh/ct/legis_intern/ddh_bib_inter_universal.htm>. Acesso em: 1 ago. 2012.

PATTO, Maria Helena S. A Produção do Fracasso Escolar: histórias de submissão e rebeldia. 3. Ed. São Paulo: Casa do psicólogo, 2008.

PESSOTTI, Isaias. Deficiência Mental: da superstição à ciência. São Paulo: T. A. Queiroz: Editora da Universidade de São Paulo, 1984.

PINHEIRO, Humberto L. As Políticas Públicas e as Pessoas Portadoras de Deficiência. In: SILVA, Shirley; VIZIM, Marli. Políticas Públicas: educação, tecnologias e pessoas com deficiências. Campinas: Mercado de Letras, 2009. P. 101-123. PIRES, Nise. Educação Especial em Foco. Rio de Janeiro: Centro Brasileiro de Pesquisas Educacionais, 1974.

REGO, Teresa C. Memórias de Escola: cultura escolar e constituição de singularidades. Petrópolis, Rio de Janeiro: Vozes, 2003.

SARAIVA, Terezinha. Educação à Distância no Brasil: lições da história. Em Aberto, Ano 16, n. 70, p. 17-27, Brasília, 1996. Disponível em: <http://www.emaberto.inep.gov.br/index.php/emaberto/article/viewFile/1048/950>. Acesso em: 5 mar. 2013

ZAGO, Nadir. Do Acesso à Permanência no Ensino Superior: percursos de estudantes universitários de camadas populares. Revista Brasileira de Educação, ANPED, v. 11, n. 32, p. 226-237, 2006.

Rosimeire Maria Orlando é professora Adjunta da Universidade Federal de São Carlos. Docente da Licenciatura em Educação Especial e do Programa de Pós Graduação em Educação Especial, campus São Carlos. Pesquisadora do Núcleo de Estudos e Pesquisas em Direito à Educação-Educação Especial. Doutora em Educação Escolar pela Universidade Estadual Paulista Julio de Mesquita Filho/UNESP/Araraquara.

E-mail: meiremorlando@gmail.com

Katia Regina Moreno Caiado é professora associada da Universidade Federal de São Carlos. Docente do Programa de Pós Graduação em Educação Especial, campus São Carlos e no Programa de Pós Graduação em Educação, campus Sorocaba. Coordenadora do Núcleo de Estudos e Pesquisas em Direito à Educação-Educação Especial. Doutora em Educação pela Universidade de São Paulo.

E-mail: caiado.katia@gmail.com 